\section{VOORVERONDERSTELLINGS IN DIE HANTERING VAN DIE VERHOUDING TUSSEN OU EN NUWE TESTAMENT. 'N BESKRYWING NA AANLEIDING VAN FRIEDRICH BAUMGÄRTEL}

\author{
S.J.P.K. Riekert ${ }^{1}$
}

\title{
ABSTRACT
}

\section{PRESUPPOSITIONS IN THE TREATMENT OF THE RELATIONSHIP BETWEEN THE OLD AND THE NEW TESTAMENT. A DESCRIPTION ACCORDING TO FRIEDRICH BAUMGÄRTEL}

The merit of Baumgärtel's treatment of expressing the relationship between the Testaments in four statements lies in his emphasising the importance of theological presuppositions. Because these presuppositions are not to be argued as expressions of faith, and because every scientific work is based on such presuppositions, this article discusses the following six presuppositions as statements for describing the relationship between the Old and the New Testament.

1. The Bible as canon has authority for the Christian believer.

2. The Bible or Canon comprises two Testaments.

3. Both the Old and the New Testament convey the powerful word of God.

4. Once the believer is touched by the gospel, he experiences the Old Testament as a witness about Christ.

5. This presupposition paves the way for a theological understanding.

6. The Old Testament should be respected as the revelation before Christ.

Wanneer Baumgärtel (โ1969], 1971) vier stellings ten opsigte van die Ou-Testamentiese hermeneutiek ontwikkel, reken hy dat die stellings hom te staan bring voor vrae van die teologie, soos die teologie as wetenskap, die rol van historiese denke, die verhouding tussen bib-

1 Prof. S.P.J.K. Riekert, Hoof: Departement Bybel- en Godsdienskunde, Fakulteit Teologie, Universiteit van die Vrystaat, Posbus 339, Bloemfontein, 9300. E-pos: riekerts.rd@mail.uovs.ac.za 
liologie en dogmatologie (sistematiese teologie), sake rakende die geskiedenis van die teologie, die verhouding geloof-openbaring-Woord van God, die verstaan van die Skrif, konfessionele binding van die teoloog, ensovoorts. Met hierdie stellings reken hy dat hy die kern van die problematiek van die Ou-Testamentiese hermeneutiek en dus ook van die verhouding tussen die Ou en Nuwe Testament aangebied het.

Waarom dan hierdie artikel, veral met die byskrif ' $n$ beskrywing na aanleiding van Friedrich Baumgärtel? Met Bright (1967:72-3) en Snyman (1986:10-11) kan daar op die probleme van Baumgärtel se benadering gewys word. Tog wil dit voorkom asof Baumgärtel deur die keuse om sy siening deur middel van stellings aan die orde te stel, 'n ander dimensie in die debat oor die verhouding tussen Ou en Nuwe Testament wil indra. In soverre sommige van die stellings wat hier aangebied word, lyk op dié van Baumgärtel, sal nadere ondersoek daarvan toon dat daar in ' $n$ mindere of meerdere mate herinterpretasie en herrangskikking plaasgevind het. Dit is dan nie die inhoud van sy stellings wat eerstens aan die orde gestel word nie, maar die wyse waarop hy dit formuleer, naamlik as voorveronderstellings wat ophelderend verder gevoer word, maar in sy gemoed ondebatteerbaar is en sy hele siening van die Ou-Testamentiese hermeneutiek kleur. So beoog hierdie artikel om na aanleiding van Baumgärtel 'n aantal voorveronderstellings op die tafel te plaas wat bepalend is vir die wyse waarop die verhouding tussen Ou en Nuwe Testament beskryf kan word. Dus, na aanleiding van Baumgärtel word in hierdie artikel 'n aantal stellings gemaak, aangesien dit standpuntinname behels wat dieper lê as bewysbare of bewese hipoteses. Tereg wys Shin (1994:1821; vgl. Van Huyssteen 1986:6) daarop dat die dogmatiese rasionalistiese kreet van die objektiewe waarheid agterhaal is. Hy sluit aan by Gadamer se "unconditional affirmation of the 'deep truth' as the foundation of life" en beskrywing van wetenskaplike kennis as "an act of faith which properly belongs to a different dimension of life than that of theory and philosophy." Volgens Shin gee Gadamer se standpuntinname in hierdie verband ' $\mathrm{n}$ aanduiding dat die hermeneuties-filosofiese dimensie gegrond is op 'n meer fundamentele dimensie - 'n dimensie wat hy die religieuse dimensie noem. Dit is geloofskeuses. Ons kan dit debatteer, aanvaar of verwerp, maar nie 
logies bewys sodat dit "feite" word nie. Uit waardering vir Baumgärtel wat hiervan as "stellings" praat, bied hierdie artikel, afgesien van die vier stellings van Baumgärtel waarby aangesluit word, nog twee bykomend. Hulle word eerste geplaas omdat dit in 'n sekere sin stellings is wat ook die voorveronderstellings van Baumgärtel se stellings is.

\section{STELLING 1: DIE BYBEL AS KANON HET GESAG VIR DIE CHRISTUS-GELOWIGE}

Met sy definisie van kanon het Riekert (1981:21, vgl. Filson 1957:910; Kline 1972:23; Van Zyl 1974:3) benadruk dat die kanon

is the corpus of authoritative Scripture of the Christian church, even during its stages of development — including the pre-Christian towards a point of fixation.

Hierdie gesag kan veral daaraan toegeskryf word dat die kerk die kanon as gesaghebbend ervaar en aanvaar het (vgl. Filson 1957:17; Riekert 1981:25). So bely die Nederduitse Gereformeerde Kerk (1992: 2) dat die Bybel die onfeilbare norm vir leer en lewe is. Dit dra gesag, goddelike gesag (vgl. Potgieter 1990:17-8), ook volgens die belydenis van die Nederduitse Gereformeerde Kerk se beleidstuk van 1986 (gepubliseer in Potgieter 1990:60; vgl. Nederduitse Gereformeerde Kerk 2002:201-202, 205-206, 209-210). Tereg word dit gestel dat ons indringender moet vra na die aard van die Skrifgesag (vgl. Potgieter 1990:24-36). Nietemin, ontken 'n mens die gesag van die Skrif, verval die noodsaak om die Bybel en dus die verhouding tussen $\mathrm{Ou}$ en Nuwe Testament ernstig op te neem.

\section{STELLING 2: DIE EEN BYBEL OF KANON BESTAAN UIT TWEE TESTAMENTE}

Met Verhoef (1988:153; vgl. Gese 1977:9; Odendaal 1979:3, Nederduitse Gereformeerde Kerk 2002: 237-239) is die uitgangspunt

dat ons Bybel nie die Tenak (OT) is nie, maar uit twee dele bestaan, en dat dié twee dele, die Ou én Nuwe Testament, saam een Boek is.

Nie alleen die feit dat ons Bybel gepubliseer word as twee Testamente nie, maar veral die proses van kanonwording agter die een Bybel 
met die twee Testamente bevestig die verbondenheid van die twee aan mekaar (vgl. Gese 1977:9-10; Riekert 1981:27). Al verskil die twee dele in baie opsigte, verkondig hulle gesamentlik net een boodskap vir die Christelike kerk (vgl. Berkhof 1974:135; Riekert 1981: 26-7; Verhoef 1988:153). Hierdie één boodskap definieer Verhoef (1988:153-4; vgl. Van Zyl 1970:14-16; Suggit 1979:141; Snyman 1988b:135) as volg. Dit is

die verkondiging van die heilshandelinge van die drie-enige God in die gang van die Ou- en Nuwe-Testamentiese geskiedenis, en dan 'n heilshandeling wat in die Persoon en soenverdienste van Jesus Christus sy wesenlike sin en ontsluiting vind.

\section{Tereg sê Van Zyl (1970:10) dat die twee Testamente}

onlosmaaklik verbind en so in mekaar verweef [is] dat hulle nie van mekaar geskei kan word nie, al moet ons voortdurend tussen hulle onderskei.

Geen wonder dat in die Christelike erediens Ou en Nuwe Testament sáám gebruik word nie (vgl. Snyman 1988a:2). Beide Testamente word ervaar as die boek van Christus en bevat die Christus-gesentreerde openbaring (vgl. Filson 1957:16; Riekert 1981:27). So bely die NG Kerk in Potgieter (1990:64):

Die Ou Testament is in die Nuwe vervul en die Nuwe Testament is in die Oue verborge. Die Nuwe Testament help ons om Christus op 'n bepaalde wyse reeds in die Ou Testament te vind, en die $\mathrm{Ou}$ Testament wys na 'n ryker vervulling wat God in die toekoms sou bewerkstellig.

Dit roep onvermydelik dat die verhouding tussen die Testamente beskryf moet word. Die wyses waarop dit gedoen word, is so ryk gevarieerd en uit soveel verskillende perspektiewe gedoen dat ook in hierdie opsig standpunt ingeneem moet word (vgl. Baker 1976:19, 20; Gese 1977:9-10).

Sonder om in die problematiek van die omskrywing van die verhouding verstrengel te raak (vgl. Bright 1967:184-196; Van Zyl 1970; Baker 1976; Gese 1977; Odendaal 1979; Hasel 1987:145-169; Snyman 1988b), moet die implikasies van die stelling uitgespel word: Ou en Nuwe Testament is gelykelik deel van die Christelike kanon (vgl. Snyman 1991:21). 


\section{STELLING 3: DIE OU TESTAMENT IS NET SOOS DIE NUWE TESTAMENT DIE WERK- ENDE WOORD VAN GOD OOK VIR DIE NUWE-TESTAMENTIESE MENS}

As logiese uitvloeisel van stelling 1 en 2, word die Ou Testament as gesaghebbend vir die Christen aanvaar. Die aanvaarding van die gesag daarvan bring na vore die ervaring dat die Ou Testament nie alleen gesag dra nie, maar ook sy krag toon deur gehoorsaamheid af te dwing. Van Zyl (1970:17-22) wys op die besondere openbaringskarakter van die Skrif wat sowel in Ou as Nuwe Testament woord en daad omvat; tegelyk beloftewoord en realisasie is.

Sonder om Baumgärtel (1971:135, 153-4, vgl. Baker 1976:197) se groot teenstelling tussen Ou- en Nuwe-Testamentiese mens te aanvaar, kan erken word dat die gelowige as Nuwe-Testamentiese mens die hele Bybel as krag van God ervaar.

Wat bewerk dit dat beide die Ou- en Nuwe-Testamentiese gelowige die Ou Testament as die krag van God vir hulle ervaar? Baumgärtel (1971:151-155) reken dat die aanspraak wat die Christen vandag ervaar reeds teenwoordig was in die aanspraak wat tot die vrome mens van die Ou Testament gekom het. Dit gaan terug tot dieselfde fundamentele belewing van ' $n$ affiniteit tussen die Nuwe-Testamentiese gelowige en die Ou Testament, vir Baumgärtel 'n wete deur die geloof dat die grondliggende belofte van die Ou Verbond in Jesus Christus gerealiseer is. Anders gesê, in die wete dat die Ou Testament deur die Christen slegs in samehang met die Nuwe Testament gelees word (vgl. stelling 2). Tog kan die Ou Testament slegs vir die Nuwe-Testamentiese mens gesag hê as juis die Ou-Testamentiese Woord. Slegs as die getuienis van die evangelie, en deel van die evangelie het dit gesag vir die Nuwe-Testamentiese gelowige en is dit die aktiewe Woord van God. 


\section{STELLING 4: 'N CHRISTUS-GEGREPENHEID MAAK 'N CHRISTELIKE VERSTAAN VAN DIE OU TESTAMENT MOONTLIK}

Tereg gaan Baumgartel (1971:134, 136) van die volgende vertrekpunte uit. Die blote feit dat die Ou Testament Christelik verstaan word, behels 'n Christelike voorveronderstelling. Slegs vanuit die toedrag dat die Christen deur die evangelie in die hart gegryp is, verstaan hy/sy die Ou Testament as 'n getuienis oor Christus (soos uitgespel in stelling 2), en dus as 'n woord wat vandag nog werksaam is en gesagvol tot hom/haar kom (soos uitgespel in stelling 1).

Die Skrif se gesag word deur die gelowige mens aanvaar, deur hom/ haar wat weet dat hy/sy in 'n vertrouende ontmoeting met die Heilige geraak het. Slegs op hierdie voorveronderstelling ervaar die gelowige hoorder van die Ou Testament die gesag van hierdie Woord.

Volgens Baumgärtel (1971:149, 150) kan die Ou Testament op sigself slegs verstaan word in terme van die godsdiensgeskiedenis of die geskiedenis van vroomheid, maar nie teologies nie. Om die Woord/ Skrif te verstaan, is deelname aan die betekenis van die Woord nodig. Kongenialiteit, verwantskap, in die sin van affiniteit, is onontbeerlik vir die verstaan. Verstaan behels gegrepenheid, ingetrek wees in die magsfeer van die Woord. Verstaan behels hier die onmiddellik ingetrek wees onder 'n mag wat die geloof ken as die Uiteindelike Werklikheid. Na hierdie Werklikheid verlang die Christen, alhoewel met vrees en bewing, as die hele ondersteuning van sy lewe. Hierdie vertrouende affiniteit aan die $\mathrm{Ou}$ Testament leef aanhoudend uit 'n toegewyde en toewydende omgang met die hele Bybel as 'n saak van die beoefening van sy geloof. Daarom kan die Ou Testament Christelikteologies slegs in samehang met die Nuwe verstaan word (Baumgärtel 1971:S136-7). Soortgelyk bely die NG Kerk in Potgieter (1990:64):

Ons erken ten volle die wetenskaplike legitimiteit van 'n bestudering van die $\mathrm{Ou}$ Testament in sy historiese konteks en voorlopig losstaande van sy verhouding tot die Nuwe Testament, mits daar besef word dat dit vir die Christelike teoloog nie moontlik is om daarmee te volstaan nie. Christelik gesproke kom die bestudering van die Ou Testament eers tot sy reg as dit in samehang met die Nuwe gelees word, net soos die unieke boodskap van die Nuwe Testament eers ten volle verstaan kan word in samehang met die Oue. 
Baumgärtel (1971:152-3) beskou die belofte "Ek is die Here jou God" as 'n geldige grondslag vir die verstaan van die Ou en Nuwe Testament as 'n eenheid wat 'n gemeenskaplike lewenswortel het, tog met 'n onderskeid: die Ou Testament verwag deur die geloof die realisering van die belofte. Die Nuwe Testament weet deur die geloof dat die belofte in Jesus Christus gerealiseer is.

Kritiek teen Baumgärtel se hantering van die grondbelofte en die uitgangspunt dat die relevansie van die Ou Testament vir die Christelike geloof slegs lê in hierdie getuienis van die grondbelofte, wys op 'n geweldige verskraling van die Ou-Testamentiese boodskap (vgl. Bright 1967:73; Westermann 1971:128-33; Baker 1976:198-199; Snyman 1986:10-1). Tog sou 'n mens nietemin kan saamstem met die volgende:

Teologies gesien, moet hierdie verbondenheid van die twee Testamente op twee maniere verstaan word:

1. Ons herken onsself ook in die voor-Christus-geskiedenisse, ons beleef die oordeel oor sonde en besef die genade in Jesus Christus wanneer die $\mathrm{Ou}$ Testament ons saam met die evangelie aanspreek. Die Nederduitse Gereformeerde Kerk (2002: 239) stel dit soos volg:

Dit is 'n redelik algemene konsensus onder teoloë dat Ou en Nuwe Testament aan mekaar verbind word deur 'n historiese lyn van God se heilshandelinge wat begin in die Ou Testament en voortgesit word in die Nuwe Testament.

2. Die heilsgeskiedenis of tradisiegeskiedenis word beleef as die geskiedenis wat Ou en Nuwe Testament omvat. Dit is slegs verstaanbaar vir die een wat in Christus gegryp is omdat die OuTestamentiese gebeure teologies verstaan kan word. So vind die Ou-Testamentiese gebeure ook alleenlik vanuit die Christusgebeure dan weerklank in die gelowige getuienis van hulle wat dit opnuut beleef (Baumgärtel 1971:153- 6, vgl. Van Zyl 1970: 10-14; Gese 1977:14-30). De Roos ([s.a.]:5) sê: "Voor die eerste Christene was het Oude Testament eenvoudig de Bijbel. Zij zagen hierin Christus verkondig."

Die Ou-Testamentikus “is per slot van rekening 'n gelowige wat vanuit 'n totale geloofsverbintenis aan Jesus Christus dink" (Van Huyssteen 1986:152). 


\section{STELLING 5: 'N TEOLOGIESE VERSTAAN KAN SLEGS UITGEWERK WORD OP GROND VAN DIE VOORVERONDERSTELLING VAN 'N CHRISTUS-GEGREPENHEID}

Vanuit die hermeneutiese sirkel waarin die Christen probeer om die Ou Testament te verstaan omdat hy dit alreeds lief het as die Woord van God, moet hy probeer deurstoot na die teologiese problematiek. Die naïewe verstaan op alle terreine is persoonlik en subjektief. Die wetenskaplike verstaan poog om aan die persoonlik-individualistiese verstaan en eklektisisme te ontkom en voort te skry na 'n verstaanswyse wat op wetenskaplike reëls gebaseer is, of in terme van Van Huyssteen (1986:6-7; vgl. Strauss \& Visagie 1984:51-2) na 'n verstaanswyse wat aan kriteria vir redelikheid voldoen. Ten spyte daarvan dat die wetenskap die relatiwiteit van menslike kennis erken, poog dit om sistematies en geldend te spreek. Geldigheid van verstaan geskied waar die individuele geval in terme van die geheel van 'n logies-sistematiese samehang verstaan word (vgl. Baumgärtel 1971:134-5).

Elke Christen verstaan die Ou Testament naïef soos dit 'n appèl op hom maak. Nie alle naïewe verstaan van die Ou Testament is geldig nie. Die wetenskap probeer die geldigheid van verstaan deur die soeke na 'n metodologie verseker. Die metodologies-hermeneutiese beginsel(s) moet die naïewe verstaan van die Christen weglei van die persoonlike willekeur tot 'n gemeenskaplike, algemeen aanvaarbare verstaanswyse - 'n logiese en sistematiese verstaan gebaseer op wetenskaplikheidsbeginsels.

Teologie is wetenskap. Om die geldigheid van sy stellings en argumente te verseker, is dit noodsaaklik om 'n metodologiese werkswyse binne die grense van die algemeen wetenskaplike verstaan te ontwikkel. Hiervolgens behoort die Ou-Testamentikus weg te beweeg van die individuele verstaan tot ' $\mathrm{n}$ algemeen geldige verstaan, wat per $s e$ 'n metodologies aanvaarbare verstaan is. Teologiese verstaan as wetenskaplike verstaan behels 'n proses van verstaan deur middel van kritiese (onderskeidende en evaluerende) nadenke oor die materiaal wat verstaan moet word. Tog begin die hermeneutiese sirkel (of spiraal, desverkiesend) by die intuïtiewe verstaan wat 'n konfessionele oorsprong mag hê en wat juis subjektiwiteit in die teologie onder- 
streep. Konfessionele verskille is dus ingesluit in die beginpunt van die hermeneutiese sirkel en dus deel van die hermeneutiese vraagstuk, aldus Baumgärtel (1971:139-142; vgl. Van Huyssteen 1986:151-168).

Die algemene hermeneuties-wetenskaplike beginsels van vandag geld ook vir die teologie as wetenskap. Tog word daar telkens 'n gedagte geopper wat met die uitgangspunt wat hierbo gestel is, bots, naamlik dat die Nuwe Testament alreeds die Ou Testament vanuit ons gestelde voorveronderstelling verstaan en daarom moet ons die wyse waarop die Nuwe Testament die Ou Testament verstaan het, aanvaar as metodologies rigtinggewend vir ons teologie-beoefening. Die antwoord hierop is dat ons nie kan en wil ontken dat dié voorveronderstelling eksplisiet in die Nuwe Testament uitgespel word nie. Tog kanoniseer hierdie feit nie die metodologie waarvolgens die Ou Testament verstaan is nie. Nietemin, die intensie daarvan word gehandhaaf en dit klop met die voorveronderstelling.

Die Nuwe-Testamentiese verstaansbeginsel kan in twee opsigte nader uitgewerk word (volgens Baumgärtel 1971:145):

(i) Die bewysvoering in die Nuwe Testament vanuit die Ou-Testamentiese profesie bied weinig hulp vir ons. Kontra die populêre beskouing het die bewysvoering vanuit die profesie 'n beperkte funksie en is geensins 'n algemene verstaansbeginsel in die Nuwe Testament nie. Dit word bloot gebruik in 'n poging om bewys te lewer dat Jesus, kontra die uiterlike voorkoms, die Messias is - 'n intuïtiewe aanvaarding vanuit die Christelike voorveronderstelling.

(ii) Die tipologiese representasie van die Ou-Testamentiese getuienis behels dat die tipe aangebied word vir ons tot waarskuwing en troos. Dit is dan wesenlik 'n kantaantekening by 'n vroeëre teks. In die wetenskaplike studie van die Ou Testament gaan dit egter om die letterlik-literêre betekenis van die boek wat verstaan moet word en tot die teoloog moet spreek, en nie die geannoteerde betekenisse oor die teks nie. Op grond van die aanvaarding van die intensie van die Nuwe-Testamentiese werkswyse (dit is wat ons as die voorveronderstelling uitgespel het), werk die teologie die beginsels uit vir die verstaan deur middel van die intellektuele indringing in die Ou-Testamentiese getuienis, omskryf in terme van die algemeen aanvaarde beginsels wat vandag geldig is. 


\section{STELLING 6: DIE OU TESTAMENT SE VOOR- CHRISTUS OPENBARINGSKARAKTER MOET GERESPEKTEER WORD}

Die denke vandag toon 'n groot mate van historiese georiënteerdheid en die verkondiging van die evangelie kan nie hierdie feit omseil nie, aldus Baumgärtel (1971:144).

Vir Baumgärtel (1971:135, 147-150) is die Ou Testament 'n getuienis vanuit 'n nie-Christelike godsdiens, en die bepaling van die verhouding tussen die Ou en Nuwe Testament gaan langs die weg van die geskiedenis van die godsdiens of vroomheid of godsdiensbelewing - die innerlike houding in die teenwoordigheid van die lewende God. Tereg wys Bright (1967:73) daarop dat, miskien onbewus, Baumgärtel die Ou Testament in 'n ondergeskikte posisie ten opsigte van die Nuwe Testament plaas deurdat die Ou Testament feitlik uitsluitlik 'n opvoedkundige funksie ter voorbereiding van die evangelie kry. Baumgärtel (1971:146-9; vgl. Baker 1976:200-1) benadruk die verskil wat hy tussen Ou en Nuwe Testament sien op so 'n wyse dat daar vervreemding tussen die twee Testamente is. Tog, al wys ons hierdie vervreemding af, moet ons vra dat die Ou Testament in sy eie reg erken sal word.

Die histories-georiënteerde denke skei ons van die "metodologie" van die Nuwe Testament en van die verstaan van die Ou Testament in die tyd van die Hervorming. Wanneer ons die historiese denke laat inspeel op ons hermeneutiese vrae, dan moet ons toegee dat die $\mathrm{Ou}$ Testament 'n voor-Christus-openbaring is wat alleen Christelik en teologies korrek verstaan kan word in sy verhouding tot die Nuwe-Testamentiese openbaring. Dit kan geskied deur die Ou-Testamentiese selfverstaan te benut wanneer ons die Ou Testament in die lig van die Nuwe Testament bestudeer. Die selfverstaan van die Ou Testament is nie identies met die voorverstaan van die Nuwe Testament nie (alhoewel die affiniteit ervaar word op grond van 'n evangeliese voorverstaan).

In sy strewe om die hele Ou Testament as Woord van God metodologies korrek (sonder enige kunsmatige harmoniëring en met vermyding van elektisisme) te verstaan, kan die teologiese verstaan nie die historiese faset van die Ou Testament verontagsaam nie. Die Ou 
Testament moet in die lig van die evangelie as Ou Testament en dus eers in terme van sy selfverstaan, verstaan word. Die hermeneutiese vraag wat aandag verdien, is "Tot watter mate hoor die Christelike geloof die Woord van God in/deur die Ou Testament in die belewing van die verskil (diskontinuïteit) en verwantskap (kontinuïteit) tussen Ou en Nuwe Testament?" Die Nederduitse Gereformeerde Kerk (2002: 240, 243) gebruik die terme "gelyktydige gelyksoortigheid" en "ongelyksoortigheid" tussen Ou en Nuwe Testament.

\section{SAMEVATTING}

Die doel van hierdie artikel was om meriete te vind in Baumgärtel se vier stellings ten opsigte van die Ou-Testamentiese hermeneutiek en dit nie sonder meer af te skryf nie. Dit het geblyk dat die erkenning van die wetenskaplike se voorveronderstellings 'n al groter rol in die moderne wetenskaplike debatte speel. In hierdie verband kan Baumgärtel miskien erken word as 'n voorloper. Die vier stellings wat hy geformuleer het, kan met vrug gebruik word, maar — soos hierbo aangetoon — is dit goed om dit uit te brei tot ses.

\section{BIBLIOGRAFIE}

BAKER D L

1976. Two Testaments, one Bible. A study of some modern solutions to the theological problem of the relationship between the Old and New Testament. Leicester: Inter-Varsity Press.

\section{BAUMGÄRTEL F}

[1969] 1971. The hermeneutical problem of the Old Testament. In: C. Westerman (ed.) Essays on Old Testament Hermeneutics (Richmond: John Knox Press), pp. 134-159.

BERKHOF L

1974. Principles of Biblical interpretation. Grand Rapids: Baker Book House.

BRIGHT J

1967. The authority of the Old Testament. London: SCM Press. 


\section{De Roos S P}

[s. a.] Postille uit het Oude Testament. Nijkerk: Callenbach.

\section{FILSON F V}

1957. Which books belong in the Bible? A study of the canon. Philadelphia: Westminster.

\section{GESE H}

1977. Zur biblischen Theologie. Alttestamentliche Vorträge. Beiträge zur evangelischen Theologie. München: Kaiser. Theologische Abhandlungen. Band 78.

\section{HASEL G}

1987. Old Testament Theology: basic issues in the current debate. Grand Rapids: Eerdmans.

\section{KLINE M G}

1972. The structure of biblical authority. Grand Rapids: Eerdmans.

\section{Nederduitse Gereformeerde Kerk}

1992. So glo ons. 'n Eietydse geloofsverantwoording van die Nederduitse Gereformeerde Kerk. Wellington: Hugenote Uitgewers.

2002. Agenda vir die elfde sitting van die Algemene Sinode van die Nederduitse Gereformeerde Kerk, Pretoria, Sondag 19 Oktober 2002. Pretoria: Algemene Sinode van die Nederduitse Gereformeerde Kerk.

\section{ODENDAAL D H}

1979. Die blywende betekenis van die Ou Testament vir die kerk. In: D.H. Odendaal, B.A. Müller \& H.J.B. Combrink (reds.), Die Ou Testament vandag. Huldigingsbundel opgedra aan Prof. P.A. Verhoef (Kaapstad: NG Kerk-Uitgewers), pp. 3-25.

\section{PotGIETER P C}

1990. Skrif, dogma en verkondiging. Kaapstad: Lux Verbi.

\section{RIEKERT S J P K}

1981. Critical research and the one Christian canon comprising two Testaments. Neotestamentica 14:21-41.

\section{SHIN K-W}

1994. Postmodernism and a Christian response. Pro Rege 22(4):15-25.

\section{SNYMAN S D}

1986. Die prediking van die Ou Testament in die bedeling ná Christus. Fax Theologica (= Acta Theologica) 6(1):1-36.

1988a. Die Ou Testament in die erediens. Fax Theologica (= Acta Theologica) 8(2): 21-29.

1988b. Die verhouding tussen Ou en Nuwe Testament by Gerhard von Rad. In: W.S. Prinsloo \& W. Vosloo (reds.), In mensetaal oor God se Woord. Huldigingsbundel opgedra aan Prof. A.H. van Zyl (Kaapstad: Lux Verbi), pp. 132-140. 
1991. Die wetenskap van die Ou Testament. Tydskrif vir Christelike Wetenskap 27(3):1-21.

\section{STRAUSS D F M \& VISAGIE P J}

1984. Die verhouding tussen nie-teologiese wetenskappe en die teologie. Tydskrif vir Christelike Wetenskap 20(3 \& 4):51-79.

\section{SuGGIT J}

1979. Principles of scriptural exposition. In: W.S. Vorster (ed.), Scripture and the use of Scripture (Pretoria: University of South Africa), pp. 139-160.

\section{VAN HUYSSTEEN W}

1986. Teologie as kritiese geloofsverantwoording. Teorievorming in die sistematiese teologie. Pretoria: RGN.

\section{VAN ZYL A H}

1970. Die verhouding van die Ou en Nuwe Testament. In: W.D. Jonker, J.H. Roberts \& A.H. van Zyl (reds.), Hermeneutica. Erebundel aangebied aan Prof. E.P. Groenewald by geleentheid van sy 65e verjaarsdag, 2 Junie 1970 (Pretoria: NG Kerk-Boekhandel), pp. 9-22.

\section{VAN ZYL H C}

1988. Die Nuwe Testament se gebruik van die Ou Testament — model of norm? Fax Theologica (= Acta Theo1ogia) 8(2):37-74.

\section{VERHOEF P A}

1988. Die toekoms van Israel as hermeneutiese probleem. In: W.S. Prinsloo \& W. Vosloo (reds.), In mensetaal oor God se Woord. Huldigingsbundel opgedra aan Prof. A.H. van Zyl (Kaapstad: Lux Verbi), pp. 151-157.

\section{WESTERMANN C}

1971. Remarks on the theses of Bultmann and Baumgärtel. In: C. Westermann (ed.), Essays on Old Testament Hermeneutics (Richmond: John Knox Press), pp. 123133.

Trefwoorde

Verhouding Ou en Nuwe

Testament

Friedrich Baumgärtel

Kanon

Hermeneutiek
Keywords

Relationship between the Old and the New Testament

Friedrich Baumgärtel

Canon

Hermeneutics 